\title{
Modified percutaneous Kirschner wire with mutual linking technique in proximal humeral fracture: a technique note and preliminary results
}

\author{
Hao-Ming Chang \\ National Cheng Kung University Hospital \\ Pei-Yuan Lee \\ Department of Orthoepaedic, Show Chwan Memorial Hospital \\ Wei-Ren Su \\ National Cheng Kung University Hospital \\ Cheng-Li Lin ( $\sim$ jengli94@gmail.com ) \\ National Cheng Kung University Hospital https://orcid.org/0000-0002-7315-7709
}

\section{Technical advance}

Keywords: proximal humerus fracture; Kirschner wire

Posted Date: September 6th, 2019

DOI: https://doi.org/10.21203/rs.2.13994/v1

License: (영 This work is licensed under a Creative Commons Attribution 4.0 International License. Read Full License 


\section{Abstract}

Background: The percutaneous pinning technique (PPT) with multiple Kirschner wires (K-wires) is one of common surgical options in proximal humeral fractures. However, complications including pin migration and loss of reduction have been re-ported. We aimed to describe a novel technique employing modified percutaneous pin-ning with mutual linking for the treatment of proximal humerus fractures, which may decrease such complications. Methods: 6 patients ( 5 female, 1 male; mean age 60.1 years) received close reduction and the modified percutaneous Kirschner wire fixation with mutual linking technique. All wires were removed about 6 weeks postoperatively followed by progressive reha-bilitation. We used following radiograph to evaluate bony union, wires migration, and fragment displacement. Clinical outcomes were evaluated using range of motion of af-fected glenohumeral joint, a 1-10 visual analog score (VAS), UCLA shoulder rating score (UCLA), and the American Shoulder and Elbow Surgeons Shoulder Score (ASES). Outcomes were evaluated during the 2-month follow up and at the final follow up. Results: All cases were followed-up after an average of 12.6 months (range, 12-13.5 months). The mean of anterior forward flexion of the injured shoulder were 152.5 degrees (range, 145-160 degrees) during the 2-month follow up and 166.7 degrees (range, 150-180 degree) at the final follow up respectively. The means of the VAS, UCLA score, and the ASES of the injured shoulders were 0.3 (range, 0-1), 31.8 (range, 27-34), and 92.4 (range, 82100) respectively. No wire migrations or fracture displacements were noted in our cases. There were also no deep infection, nonunion, implant failure, or avascular necrosis of the humeral head observed during the follow-ups. Conclusions:With this modified percutaneous Kirschner wire mutual linking technique, minimal invasive approach could be achieved and additional stability was provided by mutually linking the wires to reduce pin migration and fracture displacement in proximal humeral fracture.

\section{Background}

Proximal humeral fractures are common, accounting for $4 \%$ of all fractures [1], the surgical options of which vary, including close reduction with percutaneous pinning [2, 3], plate fixation [4-7], and hemiarthroplasty [8-10]. When treating unstable or displaced fractures in the elderly with multiple comorbidities $[11,12]$ or adolescents who have an open physis $[13,14]$, the percutaneous pinning technique (PPT) with multiple Kirschner wires (K-wires) is favored due to the advantages of minimally invasive surgery [11]. The advantages include preservation of the periosteum blood supply, minimal blood loss, multi-direction fragment fixation, the possibility of surgery under brachial plexus block, less avascular necrosis [3], less soft tissue damage and shorter hospital stay $[12,15]$. Nevertheless, complications including pin migration $[3,16,17]$ and loss of reduction $[3,18,19]$ have been reported. This article describes a novel method for the treatment of proximal humerus fractures using a technique employing modified percutaneous pinning with mutual linking, which may decrease such complications.

\section{Method}

\section{Patients and study design}


From Jan 2016 through March 2017, patients with displaced proximal humeral fracture received close reduction and the modified percutaneous K-wire fixation with mutual linking technique were enrolled in our hospital.

\section{Inclusion and exclusion criteria}

.The inclusion criteria were (1) acute (injury less than 2 weeks) displaced proximal humeral fracture (AO/OTA classification 11-A C), (2) treated with modified percutaneous K-wire with mutual linking technique, and (3) having been followed-up for at least 12 months post-surgery. The exclusion criteria were (1) existing history of bone disease, (2) other combined injury, (3) previous shoulder surgery, (4) previous fracture of the clavicle, scapula, or humerus, and (5) history of ipsilateral shoulder movement limitation.

\section{Surgical Procedure}

After general anesthesia or brachial plexus block, the patient was placed in the beach-chair position. The injured extremity was prepared, draped, and freely movable. Close reduction of the fracture was achieved by manual traction and gentle manipulation; and when needed, additional wires were used as joysticks or the Kapandji technique was applied in case of difficult reductions. The fixation technique was adapted from Jaberg's technique using four to six K-wires (diameter 2-2.5mm), depending on the fragments [3] (Figs. 1-3). After reduction, two parallel wires were inserted through the greater tuberosity and anchored to the medial cortex of the humeral shaft through the fracture site; the other two parallel wires were inserted from the lateral cortex of the humeral shaft and anchored to the subchondral bone of the humeral head. Two additional parallel wires were inserted from the lateral cortex of the humeral shaft to the calcar area to provide additional stabilization (Fig. 4). Several intramedullary wires could also be applied in cases where the reduction is difficult to maintain. After K-wire application, all wires were bent at a position about $1 \mathrm{~cm}$ above the skin to prevent skin irritation, and then mutually hooked with adequate tension as a universal construct. The K-wires were then cut at appropriate lengths with a wire cutter (Figs.1d, e, Fig. 2d). The tension of the wires' links was considered adequate if no loosening was noted after applying a gentle passive range of motion of the injured shoulder. Additionally, stability of the wires' links can be augmented using cerclage rubber bands at the connection sites (Fig. 5).

\section{Postoperative Rehabilitation}

The shoulder was then immobilized with an arm sling for 4 weeks following surgery, after which all wires were removed contingent on the radiograph exam (Figs. 1c, 2c, and 3c). Patients were encouraged to start a passive pendulum exercise after removal of the wires. Assisted or active exercise without resistance was encouraged after diagnosis of radiological healing (usually 6 weeks postoperatively).

\section{Outcome measures}


We used following radiograph to evaluate bony union, wires migration, and fragment displacement. Postoperative clinical outcomes were evaluated using range of motion of affected glenohumeral joint, a 110 visual analogue score (VAS) for pain assessment, UCLA shoulder rating score (UCLA) [20], and the American Shoulder and Elbow Surgeons Shoulder Score (ASES) [21]. Outcomes were evaluated during the 2-month follow up and at the final follow up.

\section{Statistical analyses}

All parameters were analyzed statistically. Data are presented as mean and range.

\section{Results}

We identified 6 consecutive patients ( 5 women and 1 man; mean age 60.1 years; age range 16-79 years) with displaced proximal humeral fracture received close reduction and the modified percutaneous Kirschner wire fixation with mutual linking technique. All 6 patients had been injured in either a traffic accident or a simple fall (Table 1). Radiographic bony union were noted in all cases 6 weeks after surgery, and all cases were followed-up after an average of 12.6 months (range, 12-13.5 months). The mean of active abduction and anterior forward flexion of the injured shoulder were respectively 148.3 degrees (range, 135-160 degrees) and 152.5 degrees (range, 145-160 degrees) during the 2-month follow up. The mean of the anterior forward flexion at the final follow up was 166.7 degrees (range, 150-180 degree). Regarding the clinical outcomes at the final follow up, the means of the visual analogue scale (VAS), UCLA shoulder rating score (UCLA), and the American Shoulder and Elbow Surgeons Shoulder Score (ASES) of the injured shoulders were 0.3 (range, 0-1), 31.8 (range, 27-34), and 92.4 (range, 82-100) respectively (Table 1). There were no wire migrations or fracture displacements noted in our cases. There were also no deep infection, nonunion, implant failure, or avascular necrosis of the humeral head observed during the follow-ups.

\section{Discussion}

There are various treatment options for proximal humeral fractures. Although the PPT has advantages associated with minimally invasive surgery, it is sometimes difficult to achieve anatomical reduction with the PPT compared to open reduction and internal fixation (ORIF) [12]. Close reduction is very difficult to achieve anatomical reduction but suboptimal reduction. Nevertheless, several studies have revealed that satisfactory clinical results can be obtained despite suboptimal reduction of the fracture, particularly in the elderly [3, 22-24]. Similar results were also founded in our study [Fig.1-3]. Some complications related to the PPT have been reported, including pin migration $[3,16,17]$ leading to serious complications $[25,26]$, loss of reduction $[3,18,19]$, infection and arm-length discrepancy in children [24, 25].

Some efforts have been dedicated to decreasing the wire-migration rate and enhancing the stability of the pinning fixation via the use of a locking device applied to the pins (Table 2) [11, 12, 27]. One such locking device is called the "Humerus block", in which two crossed K-wires at the fracture site are held at a fixed 
angle with the block and locking screw. Additional percutaneous screws can be inserted for the fixation of other fragments [11]. Another device, Minimally Invasive Reduction and Osteosynthesis System, also called "MIROS", involves placing four pins through the fracture site and then blocking with a metallic clip above the skin [12]. A third method is called the "Hybrid technique", in which open reduction is performed and Kwires are applied and secured by an external fixator [27]. All these semi-rigid instruments achieve satisfactory clinical and radiographic outcomes, and generally have lower complication rates, lower revision rates, and lower rates of pin migration than the PPT alone [12, 27]. Moreover, the rationale of these techniques is to augment pin stability and structural strength via an external locking instrument. However, only a limited number of K-wires can be used in the humerus block and MIROS devices; namely, two wires for the humerus block and four wires for the MIROS device. Another limitation is the fixed direction for anchoring the K-wires in the locking device. Unfortunately, these limitations may lead to insufficient fragment fixation. The hybrid technique, combining multiple K-wires and an external fixator, can offer additional fixation points for the fragments; however, the bulky external fixator is the major concern. In contrast, our modified technique has the advantage of sufficient K-wires with freedom of direction and position to fix multiple fragments. The construct is smaller and more cost-effective than previous devices. In addition, the bending and mutual linking of the wires can provide additional valgus force to resist the deforming force from the deltoid and supraspinatus muscles; however, further biomechanical studies are needed to confirm this point.

There are some possible disadvantages of our technique, including pin-tract infection and immobilization in the early postoperative period. Nevertheless, we expect benefits including improved clinical outcomes, less pin migration, better stability of fragment fixation, and less overall complications compared to the PPT. We have already performed this technique on 5 patients, in whom no wire migration or fracture displacement were noted with the mutually linked K-wires. Accordingly, we believe that this technique could also be applied to other fracture fixations, such us distal radio-ulnar fracture, as well as metatarsal and metacarpal bone fractures. However, additional cases are required to clarify the clinical efficacy of our technique. Further biomechanical studies are also needed to compare our technique with the existing locking systems.

\section{Conclusion}

The proposed percutaneous Kirschner wire mutual linking technique is a modified method that exploits the advantages of the minimal invasive approach for treatment of proximal humeral fractures. With this modified technique, an unlimited number of wire fixations can be used during surgery, thereby allowing a high degree of freedom in the composition of the fixation construct. Further, additional stability is achieved by mutually linking the wires to reduce pin migration and fracture displacement.

\section{Abbreviations}

ASES The American Shoulder and Elbow Surgeons Shoulder Score

K-wires Kirschner wires

Page 5/14 
MIROS Minimally Invasive Reduction and Osteosynthesis System

ORIF Open reduction and internal fixation

PPT Percutaneous pinning technique

UCLA UCLA shoulder rating score

VAS Visual analog score

\section{Declaration}

\section{Ethics approval and consent to participate}

This was a retrospective study and all data were collected by review of chart and radiograph with anonymization. The study protocol was approved by the National Cheng Kung University Hospital Institutional Review Board (IRB: ER-98-097). Informed consent was waived by the IRB according to the regulations of ICH-GCP and Central Competent Authorities. The proof of consent to publish from study participants can be requested if needed.

\section{Consent for publication}

Not applicable

\section{Availability of data and materials}

The datasets used and analyzed during the current study are available from the corresponding author on reasonable request.

\section{Competing interests}

The authors declare that they have no competing interests.

\section{Funding}

The authors received no financial support for the research, authorship, and/or publication of this article.

\section{Authors' contributions}

HMC and PYL conceived and designed the study. HMC, PYL and WRS searched and selected relevant studies. HMC and CLL extracted and interpreted data. HMC analyzed the data. HMC and CLL wrote the 
paper. PYL and WRS revised the manuscript. All authors critically reviewed and approved the final manuscript.

\section{Acknowledgement}

Not applicable

\section{Reference}

[1] Court-Brown CM, Garg A, McQueen MM. The epidemiology of proximal humeral fractures. Acta Orthop Scand. 2001;72:365-71.

[2] Resch $\mathrm{H}$, Hubner $\mathrm{C}$, Schwaiger R. Minimally invasive reduction and osteosynthesis of articular fractures of the humeral head. Injury. 2001;32 Suppl 1:SA25-32.

[3] Jaberg H, Warner JJ, Jakob RP. Percutaneous stabilization of unstable fractures of the humerus. J Bone Joint Surg Am. 1992;74:508-15.

[4] Hintermann B, Trouillier HH, Schafer D. Rigid internal fixation of fractures of the proximal humerus in older patients. J Bone Joint Surg Br. 2000;82:1107-12.

[5] Koukakis A, Apostolou CD, Taneja T, Korres DS, Amini A. Fixation of proximal humerus fractures using the PHILOS plate: early experience. Clin Orthop Relat Res. 2006;442:115-20.

[6] Savoie FH, Geissler WB, Vander Griend RA. Open reduction and internal fixation of three-part fractures of the proximal humerus. Orthopedics. 1989;12:65-70.

[7] Cuomo F, Flatow EL, Maday MG, Miller SR, Mcllveen SJ, Bigliani LU. Open reduction and internal fixation of two- and three-part displaced surgical neck fractures of the proximal humerus. J Shoulder Elbow Surg. 1992;1:287-95.

[8] Ko JY, Yamamoto R. Surgical treatment of complex fracture of the proximal humerus. Clin Orthop Relat Res. 1996:225-37.

[9] Ruter A. [Indication and technique for shoulder endoprostheses in fractures]. Chirurg. 2001;72:1246-52.

[10] Goldman RT, Koval KJ, Cuomo F, Gallagher MA, Zuckerman JD. Functional outcome after humeral head replacement for acute three- and four-part proximal humeral fractures. J Shoulder Elbow Surg. 1995;4:81-6.

[11] Bogner R, Hubner C, Matis N, Auffarth A, Lederer S, Resch H. Minimally-invasive treatment of three- and four-part fractures of the proximal humerus in elderly patients. J Bone Joint Surg Br. 2008;90:1602-7. 
[12] Carbone S, Tangari M, Gumina S, Postacchini R, Campi A, Postacchini F. Percutaneous pinning of three- or four-part fractures of the proximal humerus in elderly patients in poor general condition: MIROS(R) versus traditional pinning. Int Orthop. 2012;36:1267-73.

[13] Di Gennaro GL, Spina M, Lampasi M, Libri R, Donzelli O. Fractures of the proximal humerus in children. Chir Organi Mov. 2008;92:89-95.

[14] Pavone V, de Cristo C, Cannavo L, Testa G, Buscema A, Condorelli G, et al. Midterm results of surgical treatment of displaced proximal humeral fractures in children. Eur J Orthop Surg Traumatol. 2016;26:4617.

[15] Muncibi F, Paez DC, Matassi F, Carulli C, Nistri L, Innocenti M. Long term results of percutaneous fixation of proximal humerus fractures. Indian J Orthop. 2012;46:664-7.

[16] Habernek H, Walch G. [Secondary wire migration following percutaneous bore wire fixation of acromioclavicular dislocation]. Aktuelle Traumatol. 1989;19:218-20.

[17] Pientka WF, 2nd, Bates CM, Webb BG. Asymptomatic Migration of a Kirschner Wire from the Proximal Aspect of the Humerus to the Thoracic Cavity: A Case Report. JBJS Case Connect. 2016;6:e77.

[18] Soete PJ, Clayson PE, Costenoble VH. Transitory percutaneous pinning in fractures of the proximal humerus. J Shoulder Elbow Surg. 1999;8:569-73.

[19] Fenichel I, Oran A, Burstein G, Perry Pritsch M. Percutaneous pinning using threaded pins as a treatment option for unstable two- and three-part fractures of the proximal humerus: a retrospective study. Int Orthop. 2006;30:153-7.

[20] Amstutz HC, Sew Hoy AL, Clarke IC. UCLA anatomic total shoulder arthroplasty. Clin Orthop Relat Res. 1981:7-20.

[21] Michener LA, McClure PW, Sennett BJ. American Shoulder and Elbow Surgeons Standardized Shoulder Assessment Form, patient self-report section: reliability, validity, and responsiveness. J Shoulder Elbow Surg. 2002;11:587-94.

[22] Chen CY, Chao EK, Tu YK, Ueng SW, Shih $\mathrm{CH}$. Closed management and percutaneous fixation of unstable proximal humerus fractures. J Trauma. 1998;45:1039-45.

[23] Neer CS, 2nd. Displaced proximal humeral fractures. II. Treatment of three-part and four-part displacement. J Bone Joint Surg Am. 1970;52:1090-103.

[24] Hohloch L, Eberbach H, Wagner FC, Strohm PC, Reising K, Sudkamp NP, et al. Age- and severityadjusted treatment of proximal humerus fractures in children and adolescents-A systematical review and meta-analysis. PLoS One. 2017;12:e0183157. 
[25] Zacharia B, Puthezhath K, Varghees I. Kirschner wire migration from subcapital humeral fracture site, causing hydropneumothorax. Chin J Traumatol. 2016;19:305-8.

[26] Freund E, Nachman R, Gips H, Hiss J. Migration of a Kirschner wire used in the fixation of a subcapital humeral fracture, causing cardiac tamponade: case report and review of literature. Am J Forensic Med Pathol. 2007;28:155-6.

[27] Blonna D, Castoldi F, Scelsi M, Rossi R, Falcone G, Assom M. The hybrid technique: potential reduction in complications related to pins mobilization in the treatment of proximal humeral fractures. J Shoulder Elbow Surg. 2010;19:1218-29.

\section{Tables}

Table 1. Demographics, injury information and clinical outcome at the final follow up.

\begin{tabular}{|c|c|c|c|c|c|c|c|}
\hline \multirow{2}{*}{$\begin{array}{c}\text { Case } \\
1\end{array}$} & \multirow{2}{*}{$\begin{array}{l}\text { Mechanism of Injury } \\
\text { Motor vehicle crash }\end{array}$} & \multirow{2}{*}{$\begin{array}{c}\text { AO/OTA classification } \\
\text { B3 }\end{array}$} & \multicolumn{4}{|c|}{$\begin{array}{l}\text { AFEASUCLA scoreASES score } \\
\text { (degree) }\end{array}$} & \multirow{2}{*}{$\begin{array}{l}\text { Follow-up } \\
13.5 \text { months }\end{array}$} \\
\hline & & & 170 & 0 & 34 & 100 & \\
\hline 2 & Motor vehicle crash & A3 & 150 & 1 & 27 & 82 & 12 months \\
\hline 3 & Motor vehicle crash & B3 & 180 & 0 & 34 & 98 & 13 months \\
\hline 4 & Fall from standing & $\mathrm{A} 1$ & 170 & 0 & 32 & 90 & 12.5 months \\
\hline 5 & Fall from standing & B2 & 160 & 1 & 30 & 88 & 12 months \\
\hline 6 & Motor vehicle crash & B3 & 170 & 0 & 34 & 96.6 & 12 months \\
\hline
\end{tabular}

VAS - visual analogue scale ; AFE - anterior forward flexion ; UCLA score - UCLA shoulder rating score ; ASES score - the American Shoulder and Elbow Surgeons Shoulder Score

Table. 2 Summary of enhancements for the Kirschner wire fixation in proximal humeral fractures. 


\begin{tabular}{|c|c|c|c|c|}
\hline & Name & Description & Advantage & Limitation \\
\hline $\begin{array}{l}\text { Bogner R } \\
\text { et al, } \\
(2008)\end{array}$ & $\begin{array}{l}\text { Humerus } \\
\text { Block }\end{array}$ & $\begin{array}{l}\text { Two crossed K-wires are held at a } \\
\text { fixed angle with the block and locking } \\
\text { screw }\end{array}$ & $\begin{array}{l}\text { Semi-rigid } \\
\text { instrument }\end{array}$ & $\begin{array}{l}\text { Only } 2 \text { wires to fix fracture } \\
\text { site with a } \\
\text { fixed direction }\end{array}$ \\
\hline $\begin{array}{l}\text { Carbone S } \\
\text { et al, } \\
(2012)\end{array}$ & MIROS & $\begin{array}{l}\text { Four wires through the fracture site } \\
\text { are blocked in a metallic clip }\end{array}$ & $\begin{array}{l}\text { Semi-rigid } \\
\text { instrument }\end{array}$ & $\begin{array}{l}\text { Only } 4 \text { intramedullary wires to } \\
\text { fix fracture site with fixed } \\
\text { direction }\end{array}$ \\
\hline $\begin{array}{l}\text { Blonna D } \\
\text { et al, } \\
(2010)\end{array}$ & $\begin{array}{l}\text { Hybrid } \\
\text { Technique }\end{array}$ & $\begin{array}{l}\text { K-wires are secured by an external } \\
\text { fixator }\end{array}$ & $\begin{array}{l}\text { Semi-rigid } \\
\text { instrument } \\
\text { Multiple } \\
\text { wires with } \\
\text { multiple } \\
\text { directions }\end{array}$ & Bulky external apparatus \\
\hline $\begin{array}{l}\text { Our } \\
\text { technique }\end{array}$ & $\begin{array}{l}\text { Mutual } \\
\text { hooking } \\
\text { technique }\end{array}$ & $\begin{array}{l}\text { K-wires are linked mutually as a } \\
\text { universal construct. }\end{array}$ & $\begin{array}{l}\text { Semi-rigid } \\
\text { instrument } \\
\text { Multiple } \\
\text { wires with } \\
\text { multiple } \\
\text { directions }\end{array}$ & \\
\hline
\end{tabular}

Note. MIROS = Minimally Invasive Reduction and Osteosynthesis System ${ }^{\circledR}$, K-wires $=$ Kirschner wires

\section{Figures}

$1 a$

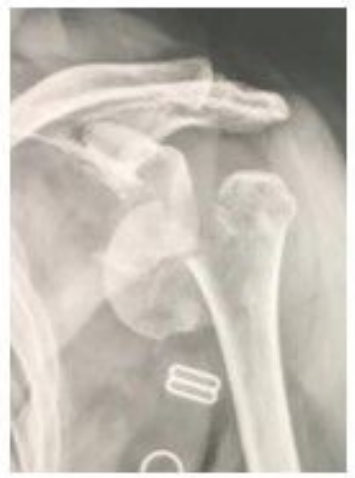

$1 d$

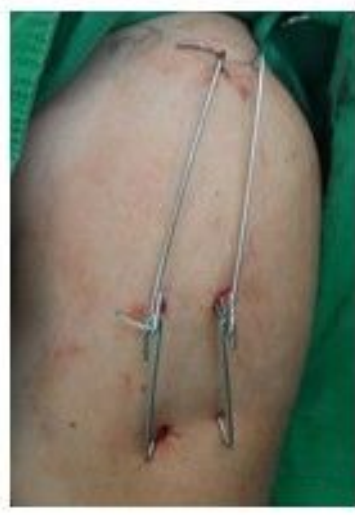

$1 b$

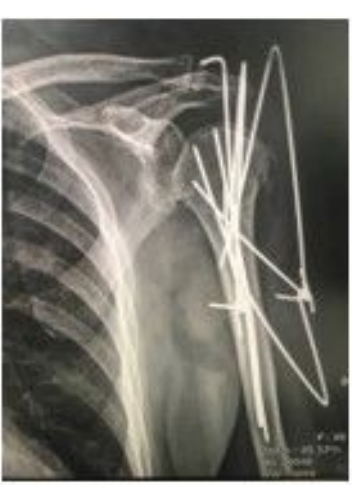

$1 \mathrm{e}$

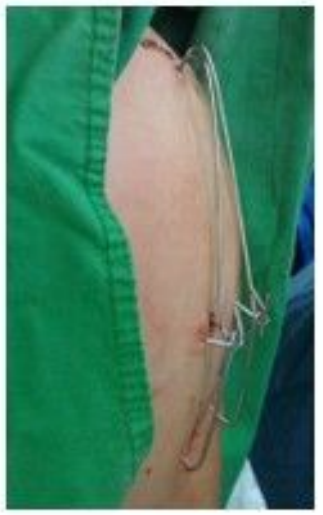

$1 c$

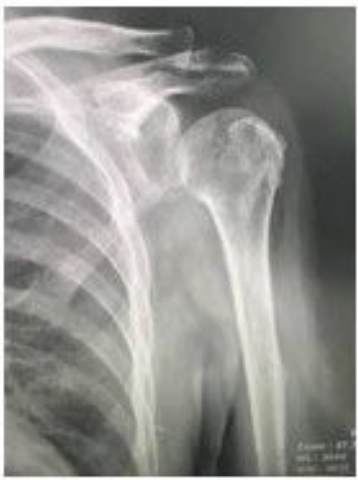

$1 f$

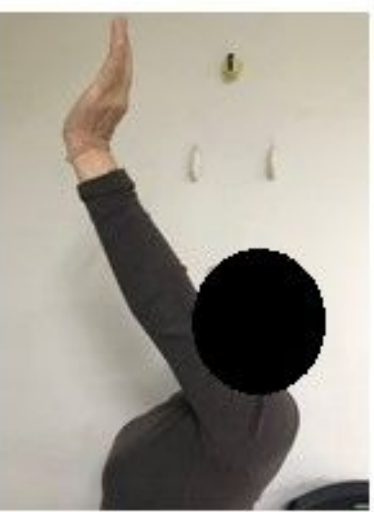


Figure 1

Case 1 a. Preoperative radiograph; b. postoperative radiograph; c. final radiograph; d. and e. Kirschner wire mutual linking technique; and, f. 2 months postoperatively.
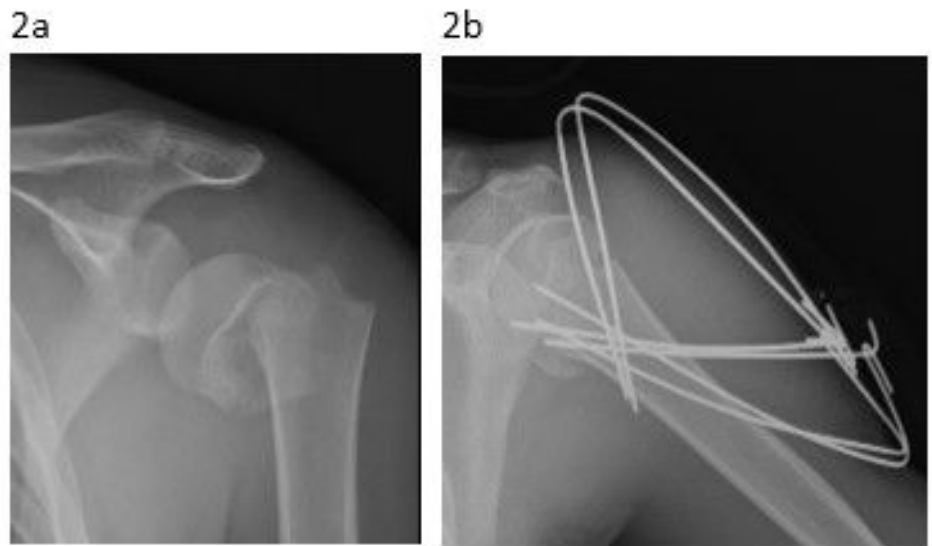

$2 \mathrm{c}$

$2 d$

$2 e$
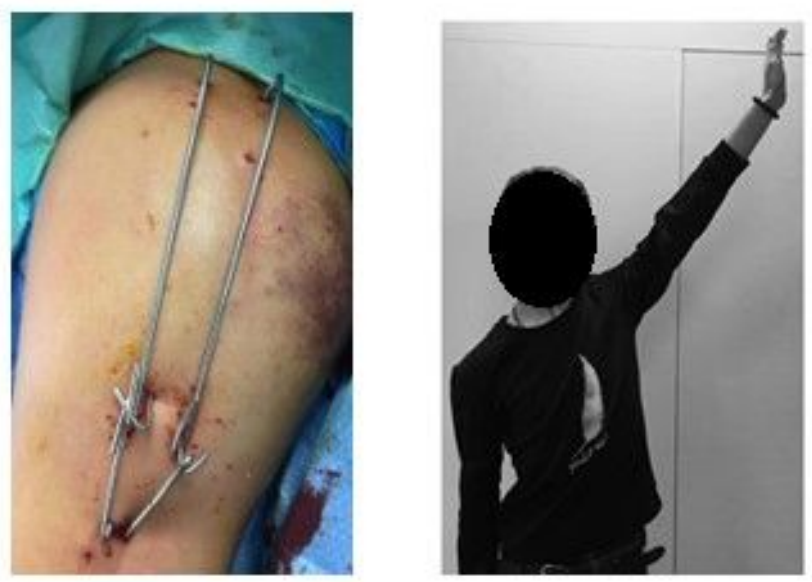

Figure 2

Case 2 a. Preoperative radiograph; b. postoperative radiograph; $c$. final radiograph; $d$. Kirschner wire mutual linking technique; and, e. 2 months postoperatively. 
3a

$3 b$

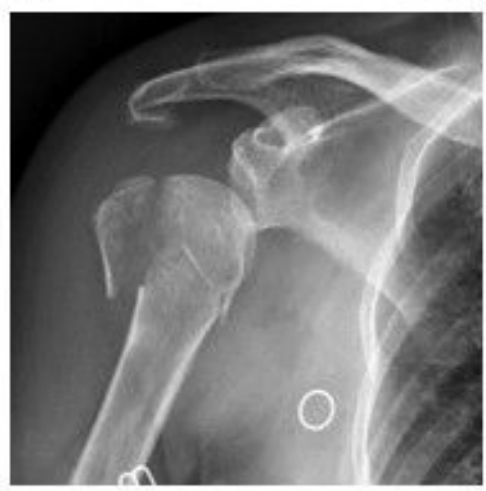

$3 d$

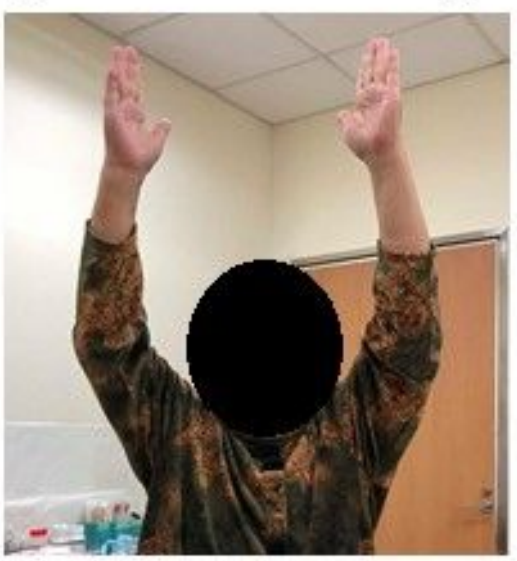

$3 c$
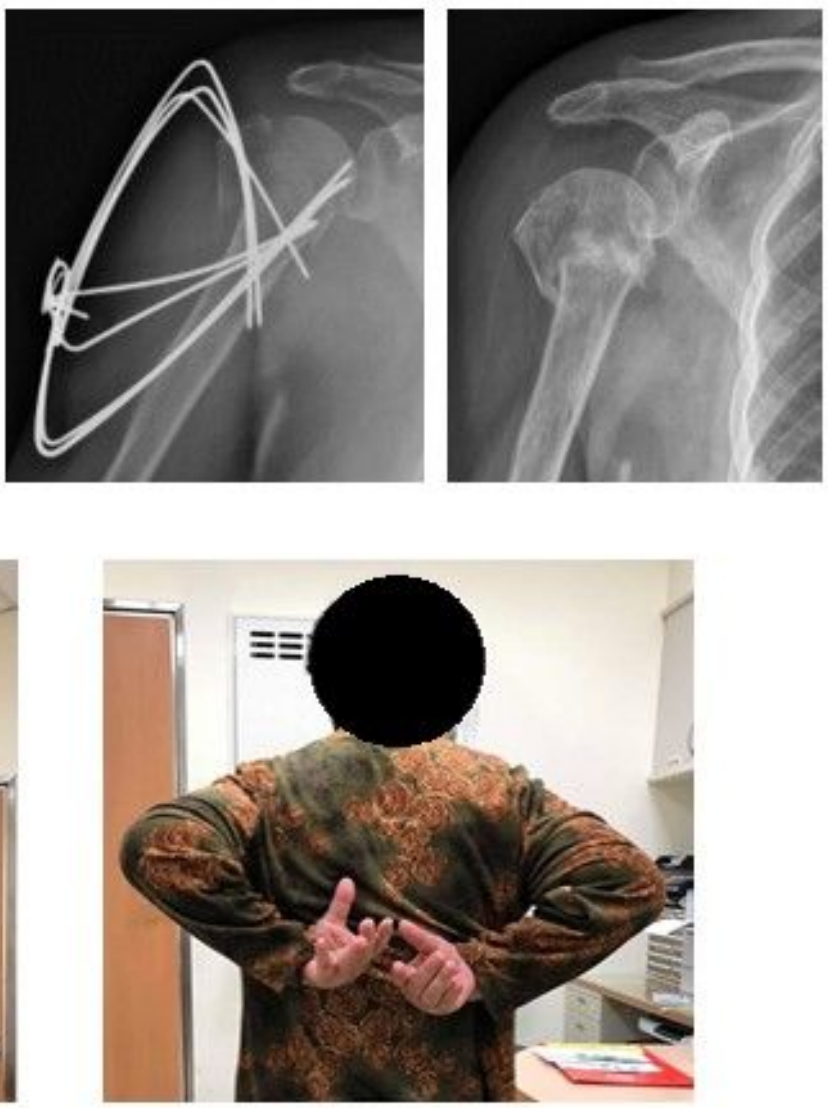

Figure 3

Case 3 a. Preoperative radiograph; b. postoperative radiograph; c. final radiograph; d, e. 2 months postoperatively. 


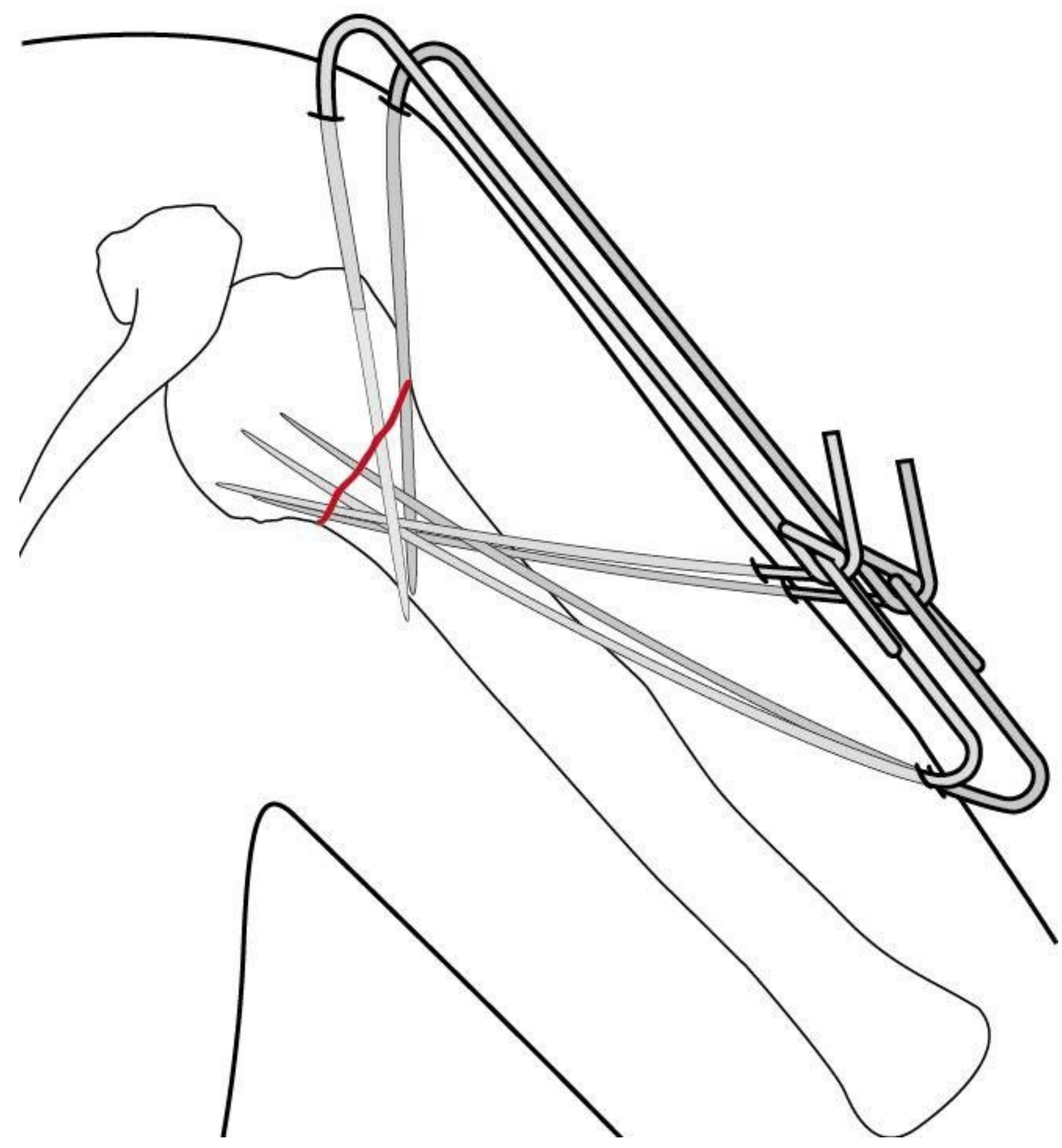

Figure 4

Schematic of the percutaneous Kirschner wires with mutual linking technique for proximal humeral fracture. 


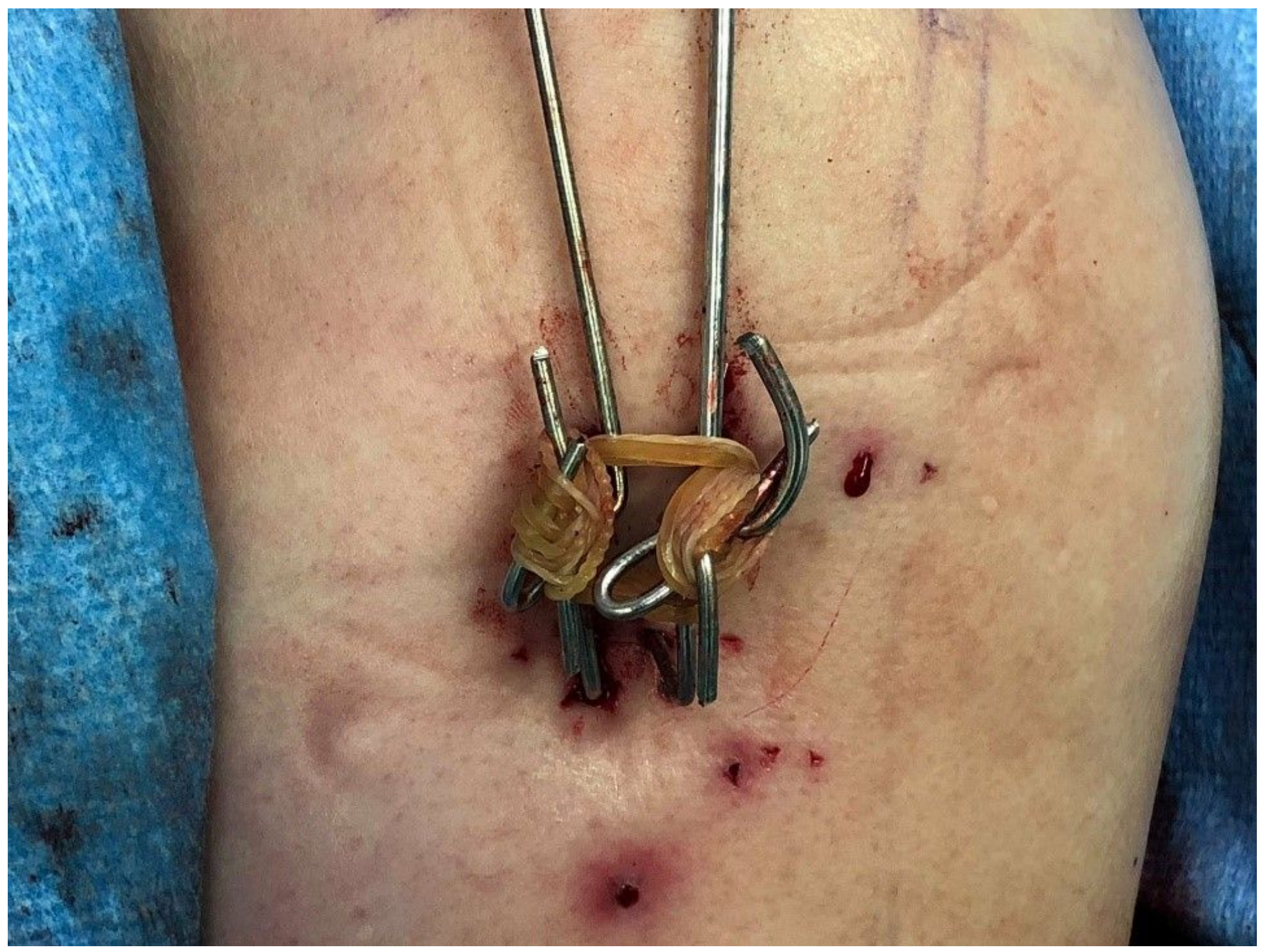

Figure 5

Cerclage rubber bands were used at the connection sites to augment the stability of the wires' links. 